\title{
Lucius Licinius Sura y la producción de vino layetano. Reflexiones en torno a una nueva marca en ánfora tarraconense
}

Lucius Licinius Sura and the Laietanian wine production. Reflections about a new stamp in Tarraconensian amfora

RAMON JÁRREGa DomíngueZ

Institut Català d'Arqueologia Clàssica (ICAC).

E-mail: rjarrega@icac.cat

Orcid ID: https://orcid.org/0000-0002-5250-2841

\section{Ramon Coll Monteagudo}

Museu Romà de Premià de Mar.

E-mail: collmr@premiademar.cat

Orcid ID: https://orcid.org/0000-0003-2118-2600

Resumen: En este estudio se plantea la posible relación del sello LLS, presente en un pivote de ánfora layetana de la forma Dressel 2 hallado en Caldes de Malavella, con la familia de Lucius Licinius Sura, notable personaje consular del siglo II d. C., y que proponemos aquí que pueda corresponder a un antepasado suyo relacionado con la producción de vino layetano o tarraconense.

Palabras Clave: Epigrafía anfórica, Hispania Citerior, elites productoras, Licinio Sura.
RECIBIDO: I 3 DE AGOSTO DE 202 | ACEPTADO: 9 DE SEPTIEMBRE DE 202।
Abstract: This study proposes the possible relationship of the LLS seal, present in a Laietanian amphora pivot of the Dressel 2 shape found in Caldes de Malavella, with the family of Lucius Licinius Sura, a notable consular of the 2 nd century AD, and which we propose here that may correspond to an ancestor of him, related to the production of Laietanian or Tarraconensian wine.

Keywords: Amphoric epigraphy, Hispania Citerior, producing elites, Licinius Sura. 


\section{INTRODUCCIÓN}

E N un reciente artículo (Járrega y Colom, 2020) presentábamos la marca L·M·N en un pivote de ánfora layetana de la forma Dressel 2, que proponíamos atribuir a un Lucius Minicius Natalis, probable antepasado de los cónsules barcinonenses homónimos del siglo II d. C. Indicábamos, como ya se había planteado anteriormente (Járrega y Colom, 2020: 235-237) que el fundus de los Minicii estuvo en la zona del actual municipio de Sant Joan Despí, en la comarca del Baix Llobregat, provincia de Barcelona. Dicha marca nos permite plantear la hipótesis de que la fortuna de los Minicii Natales padre e hijo, de época de Trajano y Adriano, pudo cimentarse en la explotación vitivinícola que llevaron a cabo sus antepasados en el ager de Barcino en el siglo I d. C., que fue objeto de comercialización, en dirección probablemente hacia Roma. Pues bien, el hallazgo reciente de otra marca de ánfora nos permite plantear el mismo origen para la fortuna de otro personaje, más significativo aún si cabe en la historia de Roma: Lucius Licinius Sura, cónsul y general de Trajano.
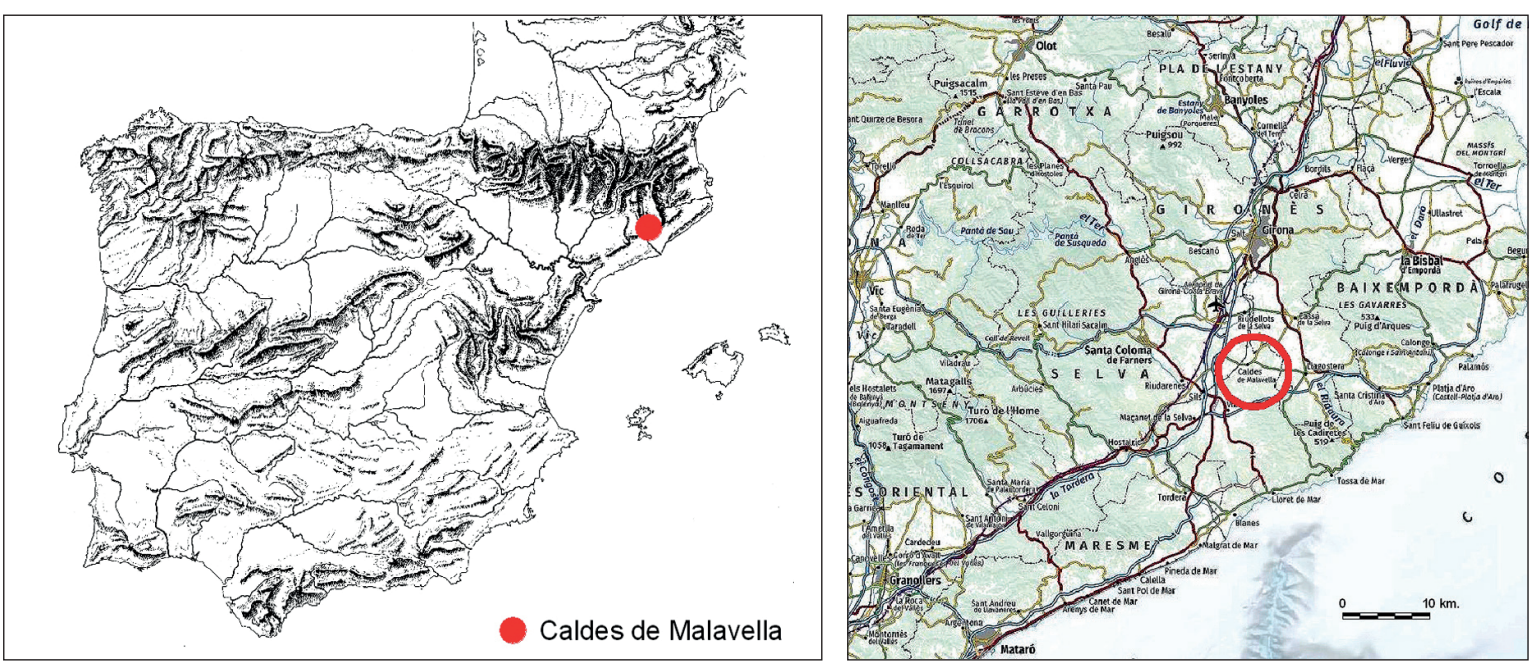

Mapa de situación de Caldes de Malavella

\section{UN NUEVO SELLO EN ÁNFORA DRESSEL 2: L·L·S}

Entre los fondos de arqueología del Museu de l'Estampació de Premià de Mar, correspondientes sobre todo a la arqueología local, se encuentra un pivote de ánfora con marca estampillada en su parte superior. La única referencia que tenemos sobre su procedencia se halla escrita con rotulador en la parte superior de la pieza, en la zona de rotura: «Caldas de Malabella» (sic). Nuestras pesquisas han resultado infructuosas a la hora de conocer las circunstancias del hallazgo de esta pieza. Así, pues, hemos de concluir que posiblemente se descubrió de forma casual en la localidad gerundense de Caldes de Malavella, y que debió ser recogida por alguno de los colaboradores del museo durante una visita a dicha localidad al observarse la existencia de la marca antes aludida. Calculamos que este hecho acaecería hacia 1970-1980, ya que el fragmento de ánfora tampoco se encontraba registrado entre los fondos del museo. 
La pieza en cuestión es un pivote completo de ánfora romana con arranque de la pared. Presenta una pasta que contiene abundante desgrasante de cuarzo y feldespato de grano medio-grande, encontrándose totalmente ausente la mica. La tonalidad varía en función de la zona: así, en el fondo interno presenta un color rojo ladrillo vivo, mientras que en la pared externa oscila entre el gris oscuro, el marrón y el rojo ladrillo vivo. Esto, sumado a que el pivote se encuentra ligeramente deformado, nos lleva a la conclusión de que se trata de una pieza defectuosa de origen. Quizá no tanto como para no ser comercializada, ya que la malformación es leve. En su parte superior presenta en cartela rectangular la marca L.L.S litteris extantibus, perfectamente legible. Justo más arriba del sello se conserva parte de un grafito ante cocturam, difícil de interpretar debido a la rotura de la pieza (quizás la parte inferior de una letra R), que se aplicó con posterioridad a la marca, ya que rompe la parte superior de la cartela (Figura 1).

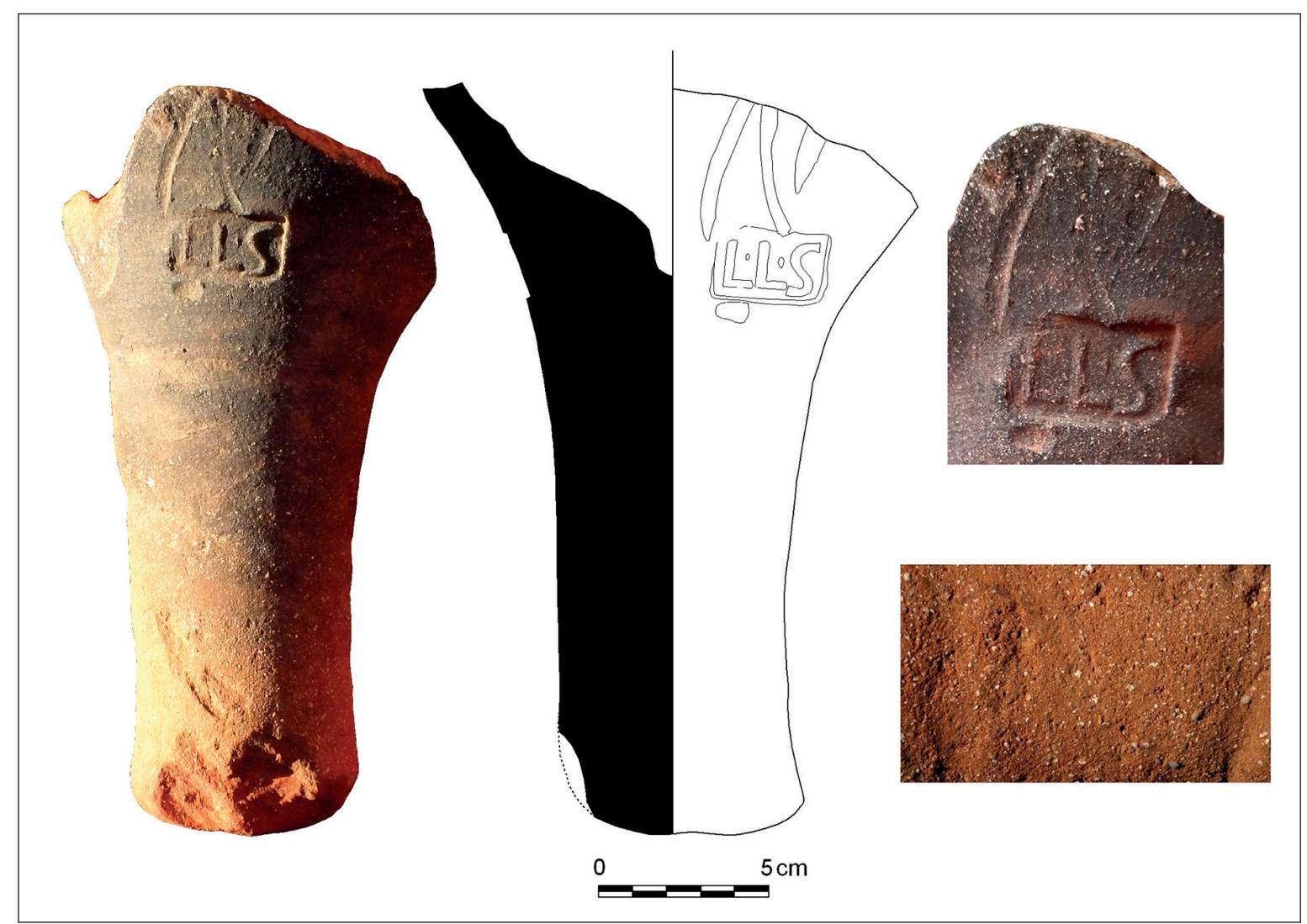

Figura 1

Fotografía y dibujo del pivote, de la marca y del grafito. Detalle de la pasta

Morfológicamente el pivote pertenece a un ánfora del tipo Dressel 2 clásica. Es de buen tamaño, bien diferente de las pequeñas bases de su predecesora, la Dressel 3. La ausencia de umbus o moldura en la base del pivote, típico de las Dressel 2 más tardías, situaría el ánfora antes del $50 \mathrm{~d}$. C. según algunos autores (Dell'Amico, Pallarès, 2007: 55, 91 ss.). Creemos que nuestra pieza, larga y maciza, puede catalogarse dentro del tipo Dressel 2 C que propone P. Berni, que se fecharía entre el 30 d. C. y el 50 d. C., 
según recientes investigaciones (Berni, 2015: 194, 199; Berni, 2017-2018: 227 ss.; Berni y Miró, 2020: 130), hecho que se constata en algunos alfares productores como por ejemplo en la fase II de Malgrat de Mar (Járrega y Berni, 2014: 396).

En cuanto a la marca, pensamos que alude claramente a unos tria nomina. No haría referencia, pues, a ningún individuo de origen servil, como en otros casos bien documentados de marcas en ánforas del tipo Dressel 2-3 (p.e., Corsi-Sciallano y Liou, 1985: 165; Miró, 1988: 237-240; Prevosti, 1995: 253; Comas, 1997: 111; Tremoleda, 2005: 116). El hecho de constar iniciales en una marca perteneciente a un ejemplar de Dressel 2 resulta relativamente normal en los pocos casos que se conocen (Járrega y Colom, 2020: 230).

Las características técnicas del pivote en cuestión le apartan de las típicas producciones de la comarca del Maresme, ya que presenta una granulometría con una gran abundancia de grano medio-grande (Figura 1), cuando lo habitual para aquella comarca es la presencia de desgrasante algo más uniforme en lo que se refiere al tamaño, y en la mayoría de casos no tan abundante. Descartamos, por las mismas razones, las zonas productivas de Barcino, del Baix Llobregat y Garraf (Darró). También el Camp de Tarragona y el área valenciana; especialmente esta última área, en la que las pastas presentan menos cantidad de desengrasante y, en general, de menor tamaño. Así, desde un punto de vista exclusivamente macroscópico, las posibilidades de origen para nuestra pieza son:

\section{Caldes de Malavella}

El lugar del hallazgo de un fragmento cerámico con leves defectos de cocción es a priori el primer candidato a tener en cuenta. Si bien es cierto que años atrás era frecuente el hallazgo de material arqueológico por la zona cercana al Puig de Sant Grau (Merino et al. 1994: 111-120; Llinàs y Nolla, 2011: 103), el principal yacimiento de la zona, como pudo ser el caso del pivote que nos ocupa, también lo es que hoy por hoy se desconoce la existencia de ningún centro productor de ánforas por las cercanías de Caldes de Malavella. Con todo, las ánforas representan con diferencia el lote más importante de los hallazgos cerámicos, con unas características técnicas muy similares a las de la cerámica común... «i que poden fer suposar l'existència d'un forn en una zona propera» (Merino et al. 1994: 113).

El probable lugar del hallazgo de nuestra pieza, el Puig de Sant Grau, alberga uno de los edificios termales de época romana más conocidos de Cataluña, que ha podido ser excavado y musealizado (entre otros, Serra Ràfols, 1941: 304-315; Nolla y Casas, 1984: 205-206; Merino et al., 1992; Merino et al., 1994; Llinàs et al., 2008: 233-242; Costa, 2011: 39-44; Llinàs y Nolla, 2011). En esencia el balneario presenta cuatro fases:

1. Fase republicana, anterior al edificio termal, con testimonios materiales de los siglos II-I a. C. En las intervenciones arqueológicas de los años 2006 y 2007 se hallaron los restos de un posible edificio de época republicana, anterior al que podemos contemplar hoy (Llinàs et al., 2008). 
2. Construcción del edificio actualmente visible, en época del emperador Claudio. Este hecho coincidiría con la cronología asignada a nuestro pivote.

3. Reformas del edificio termal en el paso de los siglos II a III d. C.

4. Fase tardía (siglo IV d. C.), mal conocida, que es cuando se produjo el abandono del establecimiento.

Un caso distinto es el del cercano Puig de les Ànimes, otro balneario romano existente en Caldes de Malavella, del que se tienen noticias desde 1876. Se sabe que tenía una piscina y que se halló un tesorillo de monedas. Fue destruido entre finales del siglo XIX e inicios del XX (Merino et al., 1994: 51-56).

Los otros yacimientos conocidos de la localidad no arrojan ninguna luz en el tema que nos interesa, ya que se trata de hallazgos poco significativos (Merino et al. 1994: 24-25).

\section{Zona más o menos próxima a Caldes de Malavella}

Relativamente cerca de esta población, sobre todo ya en la costa, se documenta la elaboración de ánforas del tipo Dressel 2 en diversos lugares:

- Villa romana dels Ametllers (Mas Carbotí), en Tossa de Mar (Revilla, 1995: 274; Nolla, 2008: 173; Palahí y Nolla, 2010: 166, 168).

- Llafranc (Nolla et al. 1982: 168-170; Nolla y Casas, 1984: 133-137; Revilla, 1995: 279-282; Nolla, 2008: 167-170; sobre todo Barti et al. 2004: 110-113).

- Fenals (Descamps y Buxó, 1986; Revilla, 1995: 273; Nolla, 2008, 165-166; sobre todo Buxó y Tremoleda, 2002: 188-194).

- Collet Est en Sant Antoni de Calonge (Nolla, 2008: 166; sobre todo Burch et al. 2015: 194).

Más difícilmente se podría considerar el alfar de Ermedàs (Cornella del Terri, comarca de Pla de 1'Estany), donde además a la Dressel 2, producida en escasa cantidad, no se le conoce epigrafía (Tremoleda et al. 2017: 428; Tremoleda y Castanyer 2017-2018: 241-242). Por las características técnicas de sus producciones tampoco parecen candidatos con posibilidades otros talleres de la zona gerundense como los de Palamós, Platja d'Aro, Viaró (Rupià) o la Caleta (Tremoleda, 2000: 122-124; Nolla, 2008: 165-173), ya que suelen presentar unas pastas mucho más depuradas que la nuestra. Distinto es el caso del alfar de Fenals, que sí presenta mica (Buxó y Tremoleda, 2002: 192). Precisamente la única marca detectada en Fenals, eso sí, sobre tegulae, es la estampilla $\mathrm{L} \cdot \mathrm{L}$ en cartela rectangular, que se ha propuesto relacionar con un Lucius Licinius (Buxó y Tremoleda, 2002: 214). 


\section{Comarca del Vallès}

Existen diversos alfares donde se ha podido documentar la producción de ánforas: Can Feu (Sabadell), en la comarca del Vallès Occidental, así como Mas Manolo, Sant Miquel dels Martres, Can Cabot (los tres en el término de Caldes de Montbui), en el Vallès Oriental, y otros, sobre los que existen completos estudios (Revilla, 1995: 209-231; más recientemente Carreras et al., 2019). Por las características de algunas de las pastas, similares a la nuestra, resulta un área geográfica nada desdeñable a la hora de considerar el origen de nuestra pieza. En este sentido resulta en extremo sugerente también la marca L·LIC... sobre dolia, documentada en Can Feu, que lógicamente se ha querido relacionar con la gens Licinia (Comas y Carreras, 2008: 184-185, Figura 3), y en la cual el praenomen es claramente un Lucius. No cabe duda que la proximidad de Caldes de Montbui a la denominada vía Augusta, como también lo es en el caso de Caldes de Malavella, pudo facilitar la circulación de productos como las ánforas vinarias.

\section{EL FUNDUS DE LOS LICINII}

Diversos topónimos recogidos en la documentación medieval se han puesto en relación con los nombres de fundi en el ager de Barcino en época romana, que originalmente harían referencia a los nomina de sus propietarios. Ello permite documentar diversos casos como Cornelianus, Paullinianus, o Sempronianus (Berni et al., 2005; Olesti, 2005 y 2008; Olesti y Carreras, 2013), o el propio topónimo Miziano, que se ha relacionado con los Minicii (Mayer 1996: 23; Járrega y Colom 2020: 235).

Uno de los nombres que aparecen en estos documentos, Lizano o Liciano, que se documenta en textos de los siglos X y XI, debe corresponder a un topónimo original Licinianus, que evidentemente hace referencia a la gens Licinia. Este topónimo, fosilizado en los actuales de Lliçà de Munt i Lliçà de Vall (comarca del Vallès Oriental, provincia de Barcelona), probablemente corresponde a un latifundio de época romana, dado que la documentación medieval del siglo X hace referencia a un Liciano Subteriore y a un Liciano Superiore (Sánchez Alguacil 2020: 306).

Se ha propuesto que el fundus Licinianus pudiese ser una propiedad de Lucius Licinius Sura, el conocido general de Trajano, o de su liberto Lucius Licinius Secundus (Rodà, 1970; Mayer, 1996: 24), este último abundantemente documentado en la epigrafía lapidaria oficial de Barcino; y se había sugerido que podía haber sido una importante propiedad vitivinícola desde antes de la época flavia. Marc Mayer llega a proponer que, así como los Minicios podían haber controlado la economía de la zona de la actual comarca del Baix Llobregat (y tal vez una parte del Vallès Occidental), lo que parece confirmarse con las recientes investigaciones (Járrega y Colom 2020: 235237), Licinio Sura podía haber dominado una buena parte del Vallès Oriental. A ello hay que añadir que P. Berni, C. Carreras y O. Olesti (2005: 183) dudan de la identificación tradicional de Granollers con la mansio Semproniana (nombre que podría hacer referencia también a un fundus), considerándola como el centro del fundus Licinianus, y relacionándola hipotéticamente con Licinio Sura. 
Por otro lado, como indican Berni, Carreras y Olesti (2005: 169-170), Marcial hace referencia a un Licinianus (Mart. 1.49,19-20), de quien destaca «las soleadas costas de Tarraco y tu Laietania» y menciona a su «querido Sura». No sabemos quién pudo ser este Licinianus, por más que Berni, Carreras y Olesti, así como J. Miró (2020: 225-226) lo identifiquen con C. Licinius Mucianus, destacado personaje de época de Nerón y Vespasiano. Además, el cognomen Licinianus hace pensar que se trata de un Licinius que debió ser adoptado por otra familia. En todo caso, la mención de Marcial permite pensar que este Licinianus era el propietario de un fundus que, a juzgar por la referencia del autor bilbilitano, podría situarse en la zona de Tarraco o en la Laietania.

De todos modos, a diferencia del caso del fundus Minicianus, que hemos atribuido a los Minicii Natales, no podemos sino limitarnos a atribuir la propiedad del fundus Licinianus a algún miembro de la gens Licinia. Sin embargo, teniendo en cuenta la importancia de Licinio Sura y de su liberto Licinio Segundo (la relación con Barcino de este último está demostrada por la epigrafía lapidaria), creemos que hace probable que guarde relación con ambos, o al menos, con el segundo.

El hecho de que los ordines de Auso (Vic) y de Iamo en Menorca (IRC IV, 83 y 89) dedicasen sendas estatuas a Licinio Secundo permite sugerir a I. Rodà (2014: 26) que los Licinios tuviesen algún interés económico en el ager Ausonensis, si bien hemos de recordar que el llano de Vic está separado del Vallès (donde se ubicaría el fundus Licinianus) por el estrecho desfiladero del Congost. Ello dificulta a nuestro entender una extensión de dicho fundus hasta el llano ausonense, si bien no impide la existencia de algún interés económico de los Licinii en dicha zona, como puede hacer pensar el pedestal de la mencionada estatua.

Por otro lado, es sugestivo relacionar con todo ello cierto M. Paullius Paullinus, personaje con un nomen poco habitual (Járrega 2018: 187) mencionado en una inscripción de Barcino (CIL II 4546 = IRC I, 98), en la que consta su amistad con L. Licinio Sura. Este Paullius probablemente se relaciona con un fundus Paullinianus, que corresponde a la actual población de Polinyà, en la comarca del Vallès Oriental, en la provincia de Barcelona (Olesti y Carreras 2008: 132 y 136; 2013: 167), y no lejos del fundus Licinianus (Polinyà está a unos $12 \mathrm{~km}$ de Granollers).

\section{LOS LICINIOS EN LA EPIGRAFÍA LAPIDARIA Y ANFÓRICA}

Cabe poner de relieve que el nomen Licinius es el sexto más abundante en Hispania (Abascal 1994), siendo el praenomen Lucius el más documentado, con 72 casos conocidos, que constituyen el 43,37 por ciento del total. Es un nomen muy habitual en la antigua Layetania, estando documentado en la epigrafía lapidaria de Barcino, Baetulo e Iluro (Berni et al. 2005). En el siglo II se generaliza la presencia de Licinii, apareciendo diversos personajes con este nomen en Barcino, Iluro e Ilerda, entre otros lugares (Berni et al. 2005: 169). 
Como recuerdan Berni, Carreras y Olesti (2005: 168) se conoce una posible exedra en Barcelona fechable por criterios epigráficos en época de Augusto (aproximadamente el 10 a. C.), en la que aparece un magistrado local llamado L. Licinius (IRC. IV.62). A ello se añaden una inscripción de Caldes de Montbui (IRC.I.36) que menciona a P. Licinius Philetus (posiblemente de origen servil, a juzgar por su cognomen) y Licinia Peregrina, de la que consta que era liberta de Crassus; otra en Terrassa (IRC.I.73), que menciona a Marcus Licinius Neitinbeles, de cognomen evidentemente indígena, y otra en Arrahona, junto a Sabadell (IRC.I.62) que menciona a Licinius Atilianus y a Licinia.

La referencia a Crassus en el epígrafe de Caldes de Montbui que menciona a Licinia Peregrina es muy interesante, pues se ha planteado que se trate de M. Licinius Crassus, familiar del famoso triunviro, que fue cónsul en el año 14 a. C. y legatus de la Hispania Citerior en los años 13-10 a. C. (Rodà 2014: 22). Ello nos permite plantear la posible relación de su familia, claramente de origen foráneo y, para más señas, procedente de Roma, con los Licinii documentados en el área productora de ánforas de Caldes de Montbui; no sabemos cuál pudo haber sido su relación, si la hubo, con los Licinii Surae. Dado que esta familia está documentada desde época de Augusto, si no antes (si tenemos en cuenta los magistrados mencionados en las monedas de Celsa, como veremos seguidamente) nos parece poco probable que tengan una relación directa con Crassus ni con sus libertos. En todo caso, este último supuesto complica y enriquece al mismo tiempo la relación de los Licinii con la producción vitivinícola y de ánforas en la zona de Caldes de Montbui.

Por otro lado, cabe recordar que Caldes de Montbui fue en época romana un balneario que atraía incluso a personajes foráneos, como el L. Minicius Apronianus (IRC, I, 34), mencionado en inscripciones de Tarraco (RIT, 23), de donde debía ser natural (Andreu, Curulla y Otiña 2006: 206). Por lo tanto, no podemos descartar que P. Licinius Philetus y Licinia Peregrina fuesen de procedencia foránea, tal vez también de Tarraco y, por lo tanto, sin ninguna relación con los Licinii que tenían su fundus en la comarca del Vallès.

En la epigrafía anfórica y doliar conocemos algunos casos que hacen referencia a Licinii, que han sido recogidos por Berni, Carreras y Olesti (2005: 172-179). En primer lugar, destaquemos una marca LICIN en Pascual 1, hallada en el pecio de Cap Béar 3 (Járrega 2016: 79), una T·LIC en Dressel 2-3, documentada en el pecio de La Chrétienne 2, que posiblemente hace referencia a un Titus Licinius (Járrega, 2018: 183-184), así como un posible P.LIC en Oberaden 74 (de la villa romana de La Llosa, en Cambrils, Tarragona), que parece hacer referencia a un Publius Licinius (Járrega 2017).

Además de estas, podemos traer a colación otras marcas menos claras (Járrega 2017), como NLIC (hallada en Badalona), NLL (del pecio de La Chrétienne H), LLC (documentada en Ampurias y Badalona), LL·Q (del alfar de Sant Miquel dels Martres, en Caldes de Montbui) y SLL (documentada también en Sant Miquel dels Martres y en el cercano taller de Can Cabot) (Carreras 2019: 153-157; Miró 2020: 225). Podrían identificarse con sendos Lucius y Sextus Licinius (y de modo bastante improbable, un 
posible Numerius Licinius), de cognomina indeterminados. Si estas identificaciones son correctas, nos permiten documentar diversos Licinii relacionados con la producción anfórica, que no sabemos si podían o no estar emparentados entre sí.

También aparecen Licinii en dolia hallados en el área catalana (Berni et al. 2005: 175-179), atestiguados por el sello [.]LICINCHRESIMI (CEIPAC 5487), documentado en Barcelona, así como en Can Feu (Sant Quirze del Vallès) y Castellarnau (Sabadell), en la comarca del Vallès Occidental, y en Santa Margarida de Montbui, en la comarca del Anoia (todos ellos en la provincia de Barcelona). Se puede interpretar sin problemas como L. Licinius Chresimus. Por otro lado, en la figlina de Can Pedrerol de Baix (Castellbisbal), donde se produjeron ánforas de la forma Dressel 2-3, se ha documentado una marca de dolium con el texto C.LIC.ADIN (Berni et al. 2005: 176). Probablemente hace referencia a un C. Licinius, de cognomen difícil de interpretar; en los índices del Corpus Inscriptionum Latinarum nos ha sido imposible localizar en ninguna parte del Imperio un cognomen cuyas primeras letras puedan corresponderse con ADIN. Esto es así ya que con toda probabilidad el cognomen ADIN hace referencia a un individuo de origen ibérico (Simón 2018 y 2020).

Llama la atención la concentración de las marcas LL·Q y y SLL, en los alfares de Sant Miquel dels Martres y Can Cabot en Caldes de Montbui, que corresponde a una ciudad romana (posiblemente denominada Aquae Calidae) en cuyo territorium tenemos documentadas diversas alfarerías productoras de ánforas. Por ello, podemos suponer una presencia importante de los Licinii en esta zona productora de vino (Sánchez Alguacil 2020: 204-295), que está a menos de $10 \mathrm{~km}$ de distancia del fundus Licinianus, con el que podrían ponerse en relación.

No podemos precisar en estos momentos si los datos de la epigrafía anfórica y en dolia indican que nos encontramos ante una única rama de la gens Licinia o si se trata de diversos Licinii sin relación directa entre sí, lo cual es probable vista la variación de nomina documentados en la epigrafía anfórica.

\section{EL ORIGEN E IMPLANTACIÓN TERRITORIAL DE LOS LICINII SURAE}

Los miembros de las élites urbanas de la zona costera de la Hispania Citerior se relacionaban entre sí. Un buen ejemplo de ello es el caso Q. Licinius Silvanus Granianus, hijo de un flamen Provinciae de origen ecuestre, que fue cónsul en el año 106 (el mismo año que Minicio Natal padre) y patrono de Baetulo (Badalona) (IRC I, 139), de donde pudo ser originario, y su hijo Quintus Licinius Silvanus Granianus Quadronius Proculus, tribuno de la sexta legión y senador en época de Nerva (IRC, I, 138). El padre aparece mencionado también en la epigrafía de Tarraco (RIT 288, 289, 321), lo que indica la movilidad de las élites provinciales en esta zona. Por otro lado, el nomen Quadronius podría indicar alguna relación familiar entre este personaje y Minicio Natal hijo, cuyo nombre completo era L. Minicius Natalis Quadronius Verus (Syme, 1982-83: 247; Fabre et al., 1997 (IRC IV): 95; Rodà, 2010: 185; Járrega y Colom 2020: 234-235). 
Todos estos datos, junto con los mencionados anteriormente, permiten pensar que la gens Licinia tuvo abundantes ramificaciones en el conventus Tarraconensis (al parecer, mucho más que la gens Minicia), y que algunos de sus miembros, concretamente Licinio Sura y Licinio Silvano Graniano (que no sabemos si tenían algún parentesco entre sí), llegaron a las más altas magistraturas del estado romano.

X. Dupré (1994) y G. Alföldy (1996) por motivos estilísticos, arquitectónicos y epigráficos consideraron que Lucius Licinius Sura que erigió el arco de Berà, cerca de Tarragona, según consta en la inscripción que aparece en el mismo (EX TESTAMENTO L.LICINI L.F.SERG.SURAE CONSACRATUM; CIL 11.428) fue un antepasado homónimo del célebre general de Trajano, de época augustea. La ausencia de titulaciones oficiales es, según Dupré, un indicio de que no se trata del personaje del siglo II, sino de un ancestro suyo. De todos modos, no deja de ser extraño que no se mencione ningún cargo, por parte de un personaje que es de suponer que debió tener una cierta relevancia política, al menos en el entorno geográfico más inmediato, es decir, Tarraco.

Ronald Syme (1981: 276 y 1982-83: 257) propuso una posible relación entre los magistrados de nombre L. Sura, al parecer padre e hijo, mencionados en las monedas de Celsa (en el actual término municipal de Velilla de Ebro, provincia de Zaragoza) de los años 39 a. C. y 14-15 d. C. y el Licinio Sura mencionado en el arco de Berà, que podría descender de los colonos itálicos establecidos en Celsa. Esta opinión sigue también Patrick LeRoux (1982: 445-446). Incluso entra dentro de lo posible que el magistrado monetal de Celsa de los años 14-15 d. C. y el constructor del arco de Berà fueran la misma persona, con lo que sería de suponer que no se desplazase a Tarraco hasta época tiberiana, que en tal caso podría ser la fecha de construcción del arco. De todos modos, la ausencia del nomen en las monedas celsenses impide comprobar si los magistrados a los que aluden pertenecían a la gens Licinia. En cualquier caso, el hecho de que el Licinio Sura mencionado en el arco de Berà perteneciera a la tribu Sergia hace posible esta atribución, dado que Celsa estaba adscrita a dicha tribu, mientras que Tarraco correspondía a la Galeria.

Es posible que el Licinius Sura constructor del arco de Berà, en el caso de que procediese de Celsa, se hubiese instalado en Tarraco, y él mismo o alguno de sus descendientes se pudo haber trasladado posteriormente a Barcino; el movimiento de las élites en la zona oriental de la Hispania Citerior es un fenómeno conocido (Miró 2020: 225), y lo ejemplifica el caso de L. Marcius Optatus, nacido en Tarraco, donde desempeñó la magistratura de edil, y que posteriormente llegó a ser duovir quinquennalis en Iluro, la actual Mataró (Járrega 2018: 192-194).

El personaje más célebre de esta familia, el Lucius Licinius Sura de época de Trajano, mencionado en la Historia Augusta (SHA Adr. II, 10) y en numerosas inscripciones, no sabemos cuándo ni por qué se estableció en Roma, donde comenzó su carrera como quattuorvir viarum curandarum en época de Domiciano, y llegó a ser 
cónsul tres veces y gobernador en Germania (Caballos 1990, páginas 183-193, núm. 103; Eck 1970, 144 n. 137, 150-152; Rodà 2014). Incluso donó a la ciudad de Roma unas termas públicas, el balneum Surae, situadas en el monte Aventino, junto a la domus que tenía en dicha colina, que menciona Marcial (Mart. VI, 64, 13). Desconocemos su lugar de nacimiento, si bien su relación con Barcino es factible, considerando que su liberto Lucius Licinius Secundus aparece mencionado en nada menos que 22 pedestales de esta ciudad (IRC.IV.83 a 104), que mencionan también a Licinius Sura, y que probablemente formaban parte de un conjunto monumental en el foro de la ciudad. Licinio Secundo aparece también mencionado en una inscripción de Sant Andreu de Llavaneres, cerca de Mataró (IRC.I.23), en el ager de Iluro. Se conoce también un fragmento arquitectónico de la primera mitad del siglo II hallado en Barcelona que menciona un L. Licinius (IRC IV 38), que pudo haber sido uno de estos dos personajes.

Es de suponer que Licinio Sura no tuviese descendencia, puesto que su liberto Licinio Secundo parece ser su heredero, según se desprende de las inscripciones conservadas.

\section{EL SELLO L·L·S Y LA IMPLICACIÓN DE LOS LICINII SURAE EN LA PRODUCCIÓN VINARIA}

Se ha planteado que el origen de la enorme fortuna del Lucius Licinius Sura del siglo II d. C. pudo originarse en la producción vitivinícola en la Hispania Citerior por parte de su familia en el siglo I d. C. (Rodà, 2014: 25). Por otro lado, como hemos visto, se ha sugerido que era el propietario del fundus Licinianus, que al parecer tuvo una importante extensión (Mayer, 1996: 24). De todos modos, hasta ahora no teníamos ningún indicio directo que pudiese relacionar a su familia con el entramado de producción y exportación vinaria a través de las ánforas.

Todas las marcas de ánforas referentes a Licinios conocidas hasta ahora, salvo quizá la de Pascual 1 con el escueto texto LICIN hallado en el pecio de Cap Béar (y que no puede ser atribuido a ningún taller en concreto) hacen referencia (no siempre clara) a diversos Licinios: un Titus Licinius, un Publius Licinius y, tal vez, sendos Lucius y Sextus Licinius. De todos ellos, solamente el penúltimo, por el praenomen (insistimos en que se trata de un caso inseguro) podría guardar relación con Licinio Sura. Ni tan solo es posible saber si estos personajes estaban emparentados entre sí o no, dada la abundancia de Licinii en Hispania, como hemos visto, y que serían tanto de origen foráneo como indígena.

En cambio, la marca que nos ocupa nos parece enormemente significativa. Recoge claramente los tria nomina de un personaje; el praenomen Lucius es evidente, y el cognomen Licinius muy probable, teniendo en cuenta su implantación en Hispania, y que otros, como Lucretius, son poco abundantes y no resultan plausibles. Nos queda 
la $\mathrm{S}$ final que, si bien no podemos considerarlo como seguro, nos parece enormemente probable que corresponda a Sura. Sin embargo, dada la cronología general de las ánforas layetanas, que no parecen ir más allá del siglo I d. C., podemos descartar una relación directa con el Licinio Sura de época de Trajano. Por ello, lo más lógico es suponer que se trata de un pariente suyo, quizás su abuelo. El paralelismo con el caso de los Minicii Natales del siglo II y su probable ancestro que marcaba ánforas con el sello L·M·N en el siglo I (Járrega y Colom 2020) nos parece muy elocuente en este sentido.

Es de lamentar la falta absoluta de contexto de este fragmento anfórico, más allá de su atribución a Caldes de Malavella, que aparece indicada en el mismo pivote. Este centro, que corresponde a una ciudad romana denominada Aquae Calidae, según indica la epigrafía, era un balneario, como el caso de Caldes de Montbui que hemos mencionado anteriormente. Por otro lado, en esta área no se conoce ningún tipo de producción anfórica, por lo que hemos de pensar que el ánfora debió llegar a Caldes de Malavella por tierra, a través de la denominada «vía Augusta» (Járrega 2020).

Por el tipo de pasta el pivote que presentamos aquí es evidentemente de origen layetano, pero ello no nos permite precisar más su procedencia como ya hemos comentado más arriba: parece poco probable que el área de origen sea el Maresme, pues a partir del análisis macroscópico no parece identificarse con la producción de esta zona. Podría corresponder a la producción del Vallès, donde hemos visto que en el área de Caldes de Montbui se documentan diversas marcas anfóricas relacionadas con los Licinii.

La probable relación de la marca L·L·S con un Lucius Licinius Sura, junto con la atribución del sello L·M·N a un Lucius Minicius Natalis (Járrega y Colom 2000), permiten plantear la implicación de los miembros de las élites provinciales en la explotación vitivinícola, como en su momento propuso V. Revilla (2002), si bien no podemos descartar la concurrencia de otros personajes o grupos sociales en esta actividad productiva. En todo caso, la fortuna de los personajes consulares del siglo II de ambas familias, aunque se cimentase en dicho tipo de explotación, no pudo continuar a lo largo del siglo II, puesto que, a excepción de la zona de Tarraco (Járrega y Otiña 2008), el vino layetano dejó cuando menos de exportarse a finales del siglo I d. C., con la desaparición de las ánforas vinarias que lo contenían. Desconocemos la causa de ello, que no parece relacionarse (al menos, no únicamente) con el controvertido edicto de Domiciano (Suetonio, Dom. 7, 2 y 14, 2), que ordenaba arrancar la mitad de las cepas de las provincias, se ha supuesto que para favorecer a la producción itálica, si bien hasta el presente no existe una investigación histórica clara sobre su sentido y alcance, y es objeto de debate entre los historiadores (Pereira, 1987). Por ello, el patrimonio de estos personajes en el siglo II debió estar basado en otros elementos, como probablemente la explotación de propiedades en otras provincias, si bien el origen de sus fortunas parece haber sido la explotación vitivinícola desarrollada por sus antepasados en la centuria anterior. 


\section{CONCLUSIONES}

- La documentación medieval de los siglos IX y X indican un topónimo, Lizano o Liciniano, que se puede relacionar con un fundus Licinianus, que parece haber tenido una extensión considerable. Aunque no existe una prueba segura de ello, se ha relacionado con el célebre Lucius Licinius Sura, cónsul y estrecho colaborador del emperador Trajano.

- El nomen Licinius es uno de los más abundantemente documentados en Hispania, y aparece documentado en la epigrafía anfórica, en ánforas Pascual 1 y, especialmente, Dressel 2, que hacen referencia a diversos Licinii (Titus Licinus, Publius Licinius y, quizás, Lucius y Sextus Licinius) que no sabemos si tenían parentesco entre sí.

- No conocemos con precisión los centros productores de ánforas con marcas de los Licinii, aunque los datos apuntan a la zona de Caldes de Montbui, en la actual comarca del Vallès Oriental. De todos modos, las tégulas con marca LL de Fenals, en Lloret de Mar, nos permiten apuntar alternativamente a dicha alfarería.

- El sello L·L·S nos permite documentar la probable identificación con Lucius Licinius Sura que, dada la cronología del ánfora (mediados o inicios de la segunda mitad del siglo I d. C.) debió ser un antepasado del homónimo personaje de la época de Trajano.

- El caso de Lucius Licinius Sura, junto con el de Lucius Minicius Natalis, permite documentar con un alto grado de probabilidad la implicación de las élites urbanas en la producción y explotación del vino layetano, lo que permitió a sus descendientes en el siglo II llevar a cabo una carrera senatorial. 


\section{REFERENCIAS BIBLIOGRÁFICAS}

ABASCAL, J. M. (1994): Los nombres personales en las inscripciones latinas de Hispania, Murcia.

ALFÖLDY, G. (1975): Die Römischen Inschrinften von Tarraco (= RIT), Madrider Forschungen 10, Deutsches Archäologisches Institut, Berlín.

ALFÖLDY, G. (1996): «Der römische Bogenüber derVia Augusta bei Tarraco (Arc de Berà) und seine Inschrift», Klio, 78, páginas 158-170.

ANDREU, J.; CURULLA, O.; OTIÑA, P. 2006: Un nuevo documento sobre los Minicii de Tarraco, Butlletí Arqueològic, 28, páginas 199-210.

BARTI, A.; PLANA, R.; TREMOLEDA, J. (2004): Llafranc romà. Quaderns de Palafrugell, 13. Ajuntament de Palafrugell-Diputació de Girona. Palafrugell.

BERNI, P. (2015): «Novedades sobre la tipología de las ánforas Dressel 2-4 tarraconenses», Archivo Español de Arqueología, 88, páginas 187-201.

BERNI, P. (2017-2018): «Dynamiques économiques de la production et du commerce des amphores Dressel 3-2 léétaniennes», en MAUNÉ, S.; BIGOT, F.; CORBEEL, J. (dirs.): Dossier. Recherches récentes sur les ateliers de production et les amphores vinaires de Gaule Narbonnaise et de Tarraconaise. Revue Archéologique de Narbonnaise, 51, páginas 227-236.

BERNI, P.; CARRERAS, C. y OLESTI, O. (2005): «La gens Licinia y el Nordeste peninsular. Una aproximación al estudio de las formas de propiedad y de gestión de un rico patrimonio familiar», Archivo Español de Arqueología, 78, páginas 167-187.

BERNI, P.; MIRÓ, J. (2020): «Le vin léétanien et de Tarraco à Carthage. Contribution de l'épigraphie à la connaissance du développement économique de la Léétanie à l'époque julio-claudienne», Antiquités Africaines, 56, páginas 129-159.

BURCH, J.; NOLLA, J.M.; TREMOLEDA, J. (2015): La alfarería romana del Collet Est (Calonge, Girona). BAR, International Series, 2770. Oxford.

BUXÓ, R.; TREMOLEDA, J. (2002): Platja de Fenals (Lloret de Mar, la Selva): una indústria terrissera d'època romana a la Costa Brava, Ajuntament de Lloret de Mar. Lloret de Mar.

CABALLOS, A. (1990): Los senadores hispanorromanos y la romanización de Hispania (siglos I-III), 2 vols., Sevilla.

CARRERAS, C. (2019): "Catàleg de marques d'àmfora, tegula, dolia i signacula del Vallès Ocidental i Oriental». En CARRERAS, C.; FOLCH, J.; GUITART, J. (2019): Laietània interior: Marques i terrisseries d'àmfores al Vallès Occidental i Oriental (Corpus International des Timbres Amphoriques, 27 - Union Académique Internationale), Barcelona.

CARRERAS, C.; FOLCH, J.; GUITART, J. (2019): Laietània interior: Marques i terrisseries d'àmfores al Vallès Occidental i Oriental (Corpus International des Timbres Amphoriques, 27 - Union Académique Internationale), Barcelona.

CEIPAC (Centro para el estudio de la interdependencia provincial en la antigüedad clásica), http://ceipac.ub.edu/

COMAS, M. (1997): Baetulo. Les marques d'àmfora, IEC-Museu de Badalona. Barcelona.

COMAS, M.; CARRERAS, C. (2008): «Les àmfores de la Laietània: estat de la qüestió». En LÓPEZ MULLOR, A.; AQUILUÉ, X. (coords.): La producció i el comerç de les àmfores de la provincia Hispania Tarraconensis, Homenatge a Ricard Pascual $i$ Guasch, Monografies, 8. Barcelona, páginas 177-188. 
CORSI-SCIALLANO, M.; LIOU, B. (1985): Les épaves de Tarraconaise à chargement d'amphores Dressel 2-4. Archaeonautica, 5 (número monográfico).

COSTA, A. (2011): «Els espais de culte a les aigües al territorium de Gerunda», en COSTA, A.; PALAHÍ, LL.; VIVÓ, D. (eds.): Aquae Sacrae: agua y sacralidad en la antigüedad = Water shapes: meanings, uses and the architecural works of the most precious gift, Girona, páginas 29-58.

DELL'AMICO, P.; PALLARÈS, F (2007): «Le anfore della Laietania. Appunti e rifflessioni», Archaeologia Maritima Mediterranea, 4, páginas 53-133.

DESCAMPS, J.; BUXÓ, R. (1986): «El jaciment romà de Platja de Fenals (Lloret de Mar, la Selva)». Tribuna d'Arqueologia 1985-1986. Barcelona, páginas 63-68.

DUPRÉ, X. (1994): L'Arc romà de Berà, Barcelona.

ECK, W. 1970: Senatoren von Vespasian bis Hadrian, München.

FABRE, G.; MAYER, M. y RODÀ, I. (1985): Inscriptions romaines de Catalogne, I. Barcelone (sauf Barcino) (= IRC I), París.

FABRE, G.; MAYER, M. y RODÀ, I. (1997): Inscriptions romaines de Catalogne, IV. Barcino (= IRC IV), París.

JÁRREGA, R. (2016): «Los nomina en las marcas de ánforas de las formas Pascual 1 y Oberaden 74 Contribución al estudio de la producción de ánforas vinarias en el noreste de la Hispania Citerior en época de Augusto», Revista d'Arqueologia de Ponent, 26, páginas 73-93.

JÁRREGA, R. (2017): «Una nueva y atípica marca en un ánfora de la forma Oberaden 74, hallada en la villa romana de La Llosa (Cambrils, Tarragona)», Boletín SECAH - Ex Officina Hispana, 8, páginas 59-61.

JÁRREGA, R. (2018): «Los nomina en la epigrafía anfórica de las ánforas Dressel 2-4 del NE de la Hispania Citerior. Cambios estructurales e implicación de las élites urbanas», Saguntum, 50, páginas 175-202.

JÁRREGA, R. (2020): «La Vía Augusta no es un topónimo. Aproximación a la organización territorial del Este de Hispania en época de Augusto», Quaderns de Prehistòria i Arqueologia de Castelló, 37, páginas 143-167.

JÁRREGA, R.; BERNI, P. (2014): «El taller de ánforas de Malgrat de Mar (Barcelona): arqueometría y epigrafía», en MORAIS, R.; FERNÁNDEZ, A.; SOUSA, M. J. (eds.): As produções cerâmicas de imitação na Hispania. Monografias Ex Officina Hispana, II, vol. I. Porto, páginas 393-403.

JÁRREGA, R.; COLOM, E. (2020): «Nueva hipótesis en torno a la presencia de élites locales de Barcino en la producción del vino layetano: el caso de Lucius Minicius Natalis». Zephyrus, LXXXV, enero-junio 2020, 1-2, páginas 229-242.

JÁRREGA, R.; OTIÑA, P. (2008): «Un tipo de ánfora tarraconense de época medioimperial (siglos II-III): la Dressel 2-4 evolucionada», SFECAG, Actes du Congrès de L'Escala - Empúries, Marsella, páginas 281-286.

LE ROUX, P. (1982): «Les sénateurs originaires de la province d'Hispania Citerior au HautEmpire romain», Epigrafia e ordine senatorio, II, Tituli, 5, páginas 439-464.

LLINÀS, J.; FRIGOLA, J.;VIVAR, G. (2008): «Resultats de les excavacions arqueològiques dels anys 2006-2007 al conjunt termal romà de Sant Grau (Caldes de Malavella, La Selva)», en J. Soler (ed.): Novenes Jornades d'Arqueologia de les Comarques de Girona, L'Escala-Empúries, vol. I, páginas 233-242. 
LLINÀS, J.; NOLLA, J. M. (2011): «Aigua sagrada. El balneari del Puig de Sant Grau a Aquae Calidae (Caldes de Malavella, la Selva)», en COSTA, A.; PALAHÍ, LL.; VIVÓ, D. (eds.): Aquae Sacrae: agua y sacralidad en la antigüedad = Water shapes: meanings, uses and the architecural works of the most precious gift. Girona, páginas 103-114.

MAYER, M. (1996): Gal.la Placídia i la Barcelona del s. V, Reial Academia de Bones Lletres, Barcelona.

MERINO, J.; NOLLA, J. M.; SANTOS, M. (1992): «El conjunt termal del Puig de Sant Grau (Caldes de Malavella, La Selva). Campanya de 1991». Primeres Jornades d'Arqueologia de les Comarques de Girona. Sant Feliu de Guíxols, páginas 62-88 + 3 láminas sin numerar.

MERINO, J.; NOLLA, J. M.; SANTOS, M. (1994): Aquae Calidae. Presència romana a la Selva. Estudis i Textos, 3, Santa Coloma de Farners.

MIRÓ, J. (1988): La producción de ánforas romanas en Catalunya. Un estudio sobre el comercio del vino de la Tarraconense (siglos I a. C.-I d. C.). BAR, International Series, 473. Londres.

MIRÓ, J. (2020): «Barcino Augustea y Julio-Claudia.Dinámica socio-económica de la producción y el comercio del vino layetano», Spal, 29.2, páginas 205-234.

NOLLA, J. M. (2008): «La producció de les àmfores tarraconenses a la Catalunya septentrional», en LÓPEZ MULLOR, A.; AQUILUÉ, X. (coords.): La producció i el comerç de les àmfores de la provincia Hispania Tarraconensis. Homenatge a Ricard Pascual $i$ Guasch. Monografies, 8, Barcelona, páginas 163-175.

NOLLA, J. M.; CANES, J. M.; ROCAS, X. (1982): «Un forn de terrissa a Llafranc (Palafrugell, Baix Empordà). Excavacions de 1980-1981», Ampurias, 44, páginas 147-183.

NOLLA, J. M.; CASAS, J. (1984): Carta Arqueològica de les comarques de Girona. El poblament d'època romana al Nord-Est de Catalunya, Girona.

OLESTI, O. (2005): «Propiedad de la tierra y élites locales. El ejemplo del ager barcinonensis». En GARRIDO-HORY, M. y GONZALES, A. (eds.): Histoire, espaces et marges de l'Antiquité: hommages à Monique Clavel-Lévêque, vol. 4. Besançon, páginas 175-200.

OLESTI, O. (2008): «Formas de propiedad y gestión de la tierra en la colonia de Barcino: una aproximación metodológica». En MANGAS, J. y NOVILLO, M. A. (eds.): El territorio de las ciudades romanas. Sísifo, Madrid, páginas 279-308.

OLESTI, O.; CARRERAS, C. (2008): New methods for the study of the social landscape from Laietania wine production region (NE Spain), New perspectives on the Ancient World (P. P. Funari, R. S. Garraffoni, B. Letalien, eds.), Oxford, páginas 131-144.

OLESTI, O.; CARRERAS, C. (2013): «Le paysage social de la production vitivinicole dans l'ager Barcinonensis: esclaves, affranchis et institores», Dialogues d'Histoire Ancienne, 39 (2), páginas 147-189.

PALAHÍ, LL.; NOLLA, J.M. (2010): Felix Turissa. La vil-la romana dels Ametllers i el seu fundus (Tossa de Mar, la Selva). Documenta, 12, Tarragona.

PEREIRA, G. 1987: El edicto de Domiciano sobre el vino y la economía política romana en el Alto Imperio, El vi a l'Antiguitat. Economia, producció i comerç al Mediterrani occidental, Badalona, páginas 349-364. 
PREVOSTI, M. (1995): «Conclusions», en PREVOSTI, M. (coord.): Autopistas i Arqueologia. Memòria de les excavacions en la prolongació de l'autopista A-19. Autopistas C.E.S.A., Barcelona, páginas 243-256.

REVILLA, V. (2002): «El vi de Tàrraco durant el Principat: èlits urbanes i imatges de la producció», Citerior: Arqueologia i ciències de l'Antiguitat, 3, páginas 173-207.

REVILLA, V. (1995): Producción cerámica, viticultura y propiedad rural en Hispania Tarraconensis (siglos I a. C.-III d. C.). Cuadernos de Arqueología, 8, L’Estaquirot. Barcelona.

RODÀ, I. (1970): «Lucius Licinius Secundus, liberto de Lucius Licinus Sura». Pyrenae, 6. Barcelona, páginas 167-183.

RODÀ, I. (2010): «La promoción de las elites en las ciudades del Conventus Tarraconensis», en NAVARRO, F. J. (ed.): Pluralidad e integración en el mundo romano, Colección Mundo Antiguo 13. Barañáin, páginas 177-188.

RODÀ, I. (2014): «Lucius Licinius Sura, Hispanus», Trajan und seine städte. Colloquium (ClujNapoca, 29. September - 2. Oktober 2013), Cluj-Napoca, páginas 21-35.

SÁNCHEZ ALGUACIL, J. (2020): «Los centros productores del vino lauronensis y las gentes implicadas en el contexto de la producción vitivinícola en el territorium de Aquae Calidae (Caldas de Montbui, Vallés Oriental, Barcelona)», Hispania Antiqva. Revista de Historia Antigua, XLIV, páginas 285-315.

SERRA RÀFOLS, J. DE C. (1941): «Las termas romanas de Caldas de Malavella (Gerona)», Archivo Español de Arqueología, 43, páginas 304-315.

SIMÓN, I. (2018): «C. Licinius Adin: uno de los últimos iberos. Dialogues d'Histoire Ancienne, 44 (1), páginas 59-73.

SIMÓN, I. (2020): Nombres ibéricos en inscripciones latinas, Rricerche sulle lingue di frammentaria attestazione Collana diretta da Paolo Poccetti. Fabrizio Serra editore, Pisa-Roma.

SYME, R. (1981): «Rival Cities, Notably Tarraco and Barcino», Ktema VI, páginas 271-285.

SYME, R. (1982-83): «Spaniards at Tivoli», AncientSociety, XIII/XIV, páginas 241-263.

TREMOLEDA, J. (2000): Industria y artesanado cerámico de época romana en el nordeste de Cataluña (Época augústea y altoimperial). BAR, International Series, 835. Oxford.

TREMOLEDA, J. (2005): «Un nou inversor itàlic en la viticultura de la Tarraconensis: Publi Baebi Tuticà». Pyrenae, 36, 2, páginas 115-140.

TREMOLEDA, J.; CASTANYER, P. (2017-2018): «La producción de ánforas vinarias en el alfar romano de Ermedàs (Cornellà del Terri, Girona)», en MAUNÉ, S.; BIGOT, F.; CORBEEL, J. (dirs.): Dossier. Recherches récentes sur les ateliers de production et les amphores vinaires de Gaule Narbonnaise et de Tarraconaise. Revue Archéologique de Narbonnaise, 51, páginas 237-256.

TREMOLEDA, J.; CASTANYER, P.; SIMON, J.; FERRER, A. (coords) (2017): La bòbila romana d'Ermedàs (Cornellà del Terri). Una indústria de producció ceràmica d'època romana al Pla de l'Estany. Grup de Recerca del Pla de l'Estany, Cornellà del Terri. 
